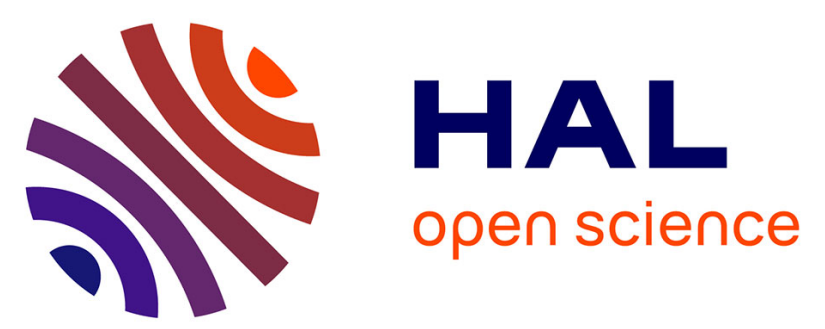

\title{
COLON CAPSULE ENDOSCOPY VERSUS COLONOSCOPY IN PATIENTS AT AVERAGE OR INCREASED RISK OF COLORECTAL CANCER
}

Sylvie Sacher-Huvelin, Emmanuel Coron, Marianne Gaudric, Lucie Planche, Robert Benamouzig, Vincent Maunoury, Bernard Filoche, Muriel Frederic, Jean-Christophe Saurin, Clement Subtil, et al.

\section{To cite this version:}

Sylvie Sacher-Huvelin, Emmanuel Coron, Marianne Gaudric, Lucie Planche, Robert Benamouzig, et al. COLON CAPSULE ENDOSCOPY VERSUS COLONOSCOPY IN PATIENTS AT AVERAGE OR INCREASED RISK OF COLORECTAL CANCER. Alimentary Pharmacology and Therapeutics, 2010, 32 (9), pp.1145. 10.1111/j.1365-2036.2010.04458.x . hal-00577003

\section{HAL Id: hal-00577003 https://hal.science/hal-00577003}

Submitted on 16 Mar 2011

HAL is a multi-disciplinary open access archive for the deposit and dissemination of scientific research documents, whether they are published or not. The documents may come from teaching and research institutions in France or abroad, or from public or private research centers.
L'archive ouverte pluridisciplinaire HAL, est destinée au dépôt et à la diffusion de documents scientifiques de niveau recherche, publiés ou non, émanant des établissements d'enseignement et de recherche français ou étrangers, des laboratoires publics ou privés. 


\begin{tabular}{l}
\hline Alimentary Pharmacology \\
\hline \& Therapeutics \\
\hline
\end{tabular}

\section{COLON CAPSULE ENDOSCOPY VERSUS COLONOSCOPY IN PATIENTS AT AVERAGE OR INCREASED RISK OF COLORECTAL CANCER}

\begin{tabular}{|c|c|}
\hline Journal: & Alimentary Pharmacology \& Therapeutics \\
\hline Manuscript ID: & APT-0511-2010.R1 \\
\hline Wiley - Manuscript type: & Clinical Trial \\
\hline $\begin{array}{r}\text { Date Submitted by the } \\
\text { Author: }\end{array}$ & 24-Aug-2010 \\
\hline Complete List of Authors: & $\begin{array}{l}\text { Sacher-Huvelin, Sylvie; Institut des Maladies de I'Appareil Digestif, } \\
\text { University Hospital, CIC } \\
\text { Coron, Emmanuel; Institut des Maladies de l'Appareil Digestif, } \\
\text { University Hospital, Gastroenterology, Hepatology and Nutritional } \\
\text { Support } \\
\text { gaudric, marianne; CHU COCHIN, GASTROENTEROLOGY } \\
\text { planche, lucie; chu hotel dieu, biostatistics } \\
\text { benamouzig, robert; chu bobigny, gastroenterology } \\
\text { maunoury, vincent; CHRU LILLE, GASTROENTEROLOGY } \\
\text { Filoche, Bernard; St. Philibert Hospital } \\
\text { FREDERIC, MURIEL; CHU NANCY, INTERNAL MEDICINE AND } \\
\text { DIGESTIVE PATHOLOGY } \\
\text { Saurin, Jean-Christophe; chu Edouard Herriot, gastroenterology } \\
\text { Subtil, Clement; CHU BORDEAUX, GASTROENTEROLOGY } \\
\text { Lecleire, Stéphane; CHU ROUEN, GASTROENTEROLOGY } \\
\text { Cellier, Christopher; HEGP, GASTROENTEROLOGY } \\
\text { Coumaros, Dimitri; CHU STRASBOURG, GASTROENTEROLOGY } \\
\text { Heresbach, Denis; Centre Hospitalier Regionale et Universitaire, } \\
\text { Service des Maladies de I'Appareil Digestif } \\
\text { Galmiche, Jean Paul; Nantes University, Gastroenterology }\end{array}$ \\
\hline Keywords: & $\begin{array}{l}\text { Colorectal cancer }<\text { Disease-based, Capsule endoscopy }<\text { Topics, } \\
\text { Colonoscopy }<\text { Topics, Diagnostic tests }<\text { Topics, Screening }< \\
\text { Topics }\end{array}$ \\
\hline
\end{tabular}

\section{SCHOLARONE ${ }^{\text {m }}$ Manuscripts}


R1 manuscript Sacher-Huvelin et al

\section{COLON CAPSULE ENDOSCOPY VERSUS COLONOSCOPY IN PATIENTS AT AVERAGE OR INCREASED RISK OF COLORECTAL CANCER}

Sylvie Sacher-Huvelin*1-2, Emmanuel Coron ${ }^{* 2}$, Marianne Gaudric ${ }^{\star * 3}$, Lucie Planche ${ }^{\star * 4}$, Robert Benamouzig ${ }^{5}$, Vincent Maunoury ${ }^{6}$, Bernard Filoche ${ }^{7}$, Muriel Frédéric ${ }^{8}$, JeanChristophe Saurin ${ }^{9}$, Clément Subtil ${ }^{10}$, Stéphane Lecleire ${ }^{11}$, Christophe Cellier ${ }^{12}$, Dimitri Coumaros $^{13}$, Denis Heresbach ${ }^{14}$ and Jean Paul Galmiche ${ }^{1,2}$

${ }^{1}$ CIC 0004, INSERM, Nantes, France

${ }^{2}$ Department of gastroenterology, IMAD, CHU and University of Nantes, France

${ }^{3}$ Department of gastroenterology, CHU Cochin, Paris, France

${ }^{4}$ Department of biostatistics, CHU Nantes, France

${ }^{5}$ Department of gastroenterology, CHU Bobigny, Paris, France

${ }^{6}$ Department of gastroenterology, CHRU Lille, France

${ }^{7}$ Department of gastroenterology, CHU St Philibert, Lomme, France

${ }^{8}$ Department of internal medicine and digestive pathology, CHU Nancy, Vandoeuvre les Nancy, France

${ }^{9}$ Department of gastroenterology, CHU E Herriot, Lyon, France

${ }^{10}$ Department of gastroenterology, CHU Bordeaux, France

${ }^{11}$ Department of gastroenterology, CHU Rouen, France

${ }^{12}$ Department of gastroenterology, HEGP, Paris, France

${ }^{13}$ Department of gastroenterology, CHU Strasbourg, France

${ }^{14}$ Department of gastroenterology, CHU Rennes, France

* Equal contribution

${ }^{* *}$ Equal contribution

\section{Corresponding author: Prof JP Galmiche}

Postal address : Department of gastroenterology, IMAD, CHU HOTEL DIEU, 44093 Nantes cedex 1, France

email: jeanpaul.galmiche@chu-nantes.fr

Tel: 33240083028

Fax: 33240083168 
R1 manuscript Sacher-Huvelin et al

\begin{abstract}
Background - Aim Colon capsule endoscopy (CCE) is a new, non-invasive technology. We conducted a prospective, multicentre trial to compare CCE and colonoscopy in asymptomatic subjects enrolled in screening or surveillance programmes for the detection of colorectal neoplasia.
\end{abstract}

Methods Patients underwent CCE on day one and colonoscopy (gold standard) on day two. CCE and colonoscopy were performed by independent endoscopists.

Results 545 patients were recruited. CCE was safe and well-tolerated. Colon cleanliness was excellent or good in $52 \%$ of cases at CCE. Five patients with cancer were detected by colonoscopy, of whom two were missed by CCE. CCE accuracy for the detection of polyps $\geq$ $6 \mathrm{~mm}$ was 39\% (95\% Cl 30-48) for sensitivity, 88\% (95\% Cl 85-91) for specificity, 47\% (95\% Cl 37-57) for positive predictive value and $85 \%(95 \% \mathrm{Cl} 82-88)$ for negative predictive value. CCE accuracy was better for the detection of advanced adenoma, in patients with good or excellent cleanliness and after re-interpretation of the CCE videos by an independent expert panel

Conclusion Although well-tolerated, CCE cannot replace colonoscopy as a first line investigation for screening and surveillance of patients at risk of cancer. Further studies should pay attention to colonic preparation. Clinicaltrial.gov number NCT00436514.

Key words: colon capsule endoscopy; colonoscopy; screening; colonic neoplasia, accuracy. 
R1 manuscript Sacher-Huvelin et al

\section{INTRODUCTION}

Colorectal cancer $(\mathrm{CRC})$ is a major cause of mortality and morbidity worldwide. The screening and surveillance of patients with average (asymptomatic, 50-74 years old), or increased (asymptomatic with a personal or family history of polyps and/or CRC), risk is based on the detection and removal of adenomatous polyps. In many countries, colonoscopy is considered to be the standard procedure for screening and surveillance. However, colonoscopy has some limitations including invasiveness, discomfort and embarrassment for the patient, the need for short-term hospitalisation and, finally, a relatively high cost. These inconveniences may limit the utility of colonoscopy, especially in screening strategies where acceptance of the test is of the utmost importance. Similarly, such disadvantages can impact on compliance in patients who require surveillance because of a personal or family history of colonic neoplasia. Capsule endoscopy is a new technology for the investigation of the small bowel, which has been developed very successfully during the last decade. Recently, a specific capsule device has been developed for colon endoscopy and proof-of-concept studies have shown encouraging results ${ }^{1-4}$. In fact, none of these studies were designed for the assessment of colon capsule endoscopy (CCE) as a screening test, as most of the enrolled patients were symptomatic and/or hospitalised for known or suspected colonic diseases.

We, therefore, conducted a prospective, multicentre trial, in order to assess the diagnostic yield of CCE compared with colonoscopy in carefully-selected, asymptomatic patients at average or increased risk of CRC. Because the likelihood of cancer is higher in polyps $\geq 6$ $\mathrm{mm}$ in size, our main criterion of judgement was the proportion of individuals with polyps of this size (or with CRC) detected by CCE, as compared with colonoscopy.

\section{PATIENTS AND METHODS}

\section{Study group}

The protocol was approved by the institutional review board of the Pays de la Loire and the study was registered in the EudraCT database ( $n^{\circ}$ ID RCB 2007-A00056-47) and in the 
R1 manuscript Sacher-Huvelin et al

database Clinicaltrial.gov ( $\mathrm{n}^{\circ}:$ NCT00436514). Written, informed consent was obtained from all patients. Adults patients were enrolled prospectively from April 2007 to July 2009 in each of the 16 French academic centres if they fulfilled one of the following two criteria: (i) healthy, asymptomatic individuals 50 to 74 years old who accept colonoscopy in the context of a screening programme (average risk group); (ii) asymptomatic patients with a personal or family history of $\mathrm{CRC}$ or polyps, but without colonoscopy during the preceding three years (increased risk group). The main exclusion criteria were ; the presence of dysphagia; symptoms suggestive of intestinal obstruction; recently-complicated colonic diverticulosis; advanced heart or kidney failure; the presence of a cardiac pace-maker or other implanted electro-medical device; pregnancy.

\section{Colon capsule endoscopy and colonoscopy}

The characteristics of PillCam colon (Given Imaging Ltd) have been described previously ${ }^{5}$. Briefly, the colon capsule uses the same technology as the small bowel corresponding devices, but is slightly longer. It measures $11 \times 32 \mathrm{~mm}$ and has dual cameras, located at both ends, allowing image acquisition with a frame rate of 4 frames per second.

The colon preparation procedure has been adapted from the conventional PEG preparation used for colonoscopy in order to ensure cleanliness, but also propulsion of the capsule through the GI tract. Patients underwent colon preparation as previously reported by others ${ }^{1}$. However, during the first part of this trial, we did not recommend a clear liquid diet the day before CCE. This recommendation was introduced after the first interim analysis planned in the study protocol (see results). Colon cleanliness was assessed using a fourgrade scale, as in previous studies, and results were expressed as excellent, good, fair or poor. The same classification was applied to assess colonic preparation during colonoscopy (after flushing of the colon, if required).

Colonoscopy was performed under general anaesthesia (as is standard practice in France). All detected polyps were removed and sent to the local Pathology Department for routine histology. 
R1 manuscript Sacher-Huvelin et al

\section{Study design (Table 1)}

The study was conducted prospectively and its design followed the STARD recommendations ${ }^{6}$. Patients at average or increased risk of CRC were enrolled in each centre and informed consent was obtained after explaining the objectives and modalities of the protocol. During this first visit, patients were instructed about the three-day, low-residue diet and the colon preparation procedure (four litres of PEG) required prior to CCE. Patients were hospitalised for approximately 36 hours. CCE was performed at approximately 10:00 a.m., one hour after the ingestion of the fourth litre of PEG. Domperidone, sodium phosphate and bisacodyl suppository were administered as previously described (Table 1). After completion of CCE (excretion of the capsule or at least 10 hours after capsule ingestion) patients were allowed to eat a light, low-residue snack in the evening of this first day. Colonoscopy was performed the morning of the second day, approximately three hours after administration of an additional litre of PEG to ensure optimal cleanliness.

In each centre, one to three experienced endoscopists performed all colonoscopies, while capsule videos were interpreted separately by one single independent endoscopist per centre. CCEs and colonoscopies were performed by endoscopists, unaware of each others findings. All capsule endoscopists received specific training using CCE videos before the beginning of the trial. The training course (one full day) consisted of showing some characteristic videos in the morning (with explanations of the method of CCE video interpretation, especially polyp size estimation) followed by a validation of the training by three test-video sequences in the afternoon. The first author certified the validation of the training session by the following criteria; (i) adequate knowledge of the software capabilities, (ii) ability to detect more than $90 \%$ of lesions $\geq 6 \mathrm{~mm}$, and (iii) estimation of polyp size.

Polyps and lesions seen during colonoscopy were recorded according to their location and size, eventually, with the use of open-biopsy forceps.

CCE videos were interpreted separately at a reading speed of approximately eight frames per second. Investigators were instructed to read the images taken from the proximal 
R1 manuscript Sacher-Huvelin et al

camera and then from the distal one. The sizes of polyps detected were estimated visually, according to the distance separating the colonic wall and the camera, as in previous trials. However, contrary to Van Gossum et al, no correction of this rough estimate was applied.

Tolerability and safety were recorded during hospitalisation and, finally, at a follow-up visit approximately 30 days after the patient was discharged from the clinic. During this visit, patients were invited to express their opinions concerning CCE and colonoscopy using a Visual Analogic Scale (VAS) for both procedures.

\section{Statistical analysis}

As in previous trials, colonoscopy was considered as the gold standard and per-patient comparisons were made considering different primary and secondary criteria. However, because colonoscopy is not a perfect gold standard, we planned an additional analysis using a modified gold standard, taking into consideration the false positive results of CCE. Indeed, so-called "false positives" are in fact "true positives" if the presence of a polyp is confirmed by a second colonoscopy. We also made the same assumption when a second independent video reading of the discrepant findings between colonoscopy and CCE, performed by an expert panel, clearly confirmed the presence of the image of a polyp $\geq 6 \mathrm{~mm}$.

According to the STARD recommendations, the analysis was performed on an intention-to-diagnose basis (with technical failures considered to be negative results of CCE). The per-protocol cohort represents the patients who completed the study successfully and who underwent both CCE and colonoscopy with complete examination.

Contrary to previous studies, which were based only on exploratory statistics, the aim of this trial was to test the non-inferiority of CCE as compared with colonoscopy. Considering the perspective of screening and surveillance, we assumed that an excellent negative predictive value (no more than 5\% difference with colonoscopy) would be indispensable for such a test to be useful in practice. In addition, even if CCE was inferior to colonoscopy, we assumed that the difference in terms of sensitivity between CCE and colonoscopy should not exceed $20 \%$. Using an $\alpha$ risk $=5 \%$, a $\beta$ risk $=10 \%$ and an expected prevalence of polyps $\geq 6$ 
R1 manuscript Sacher-Huvelin et al

$\mathrm{mm}$ of $15 \%$ (primary criterion of judgement), we calculated that a sample size of 514 (550 with losses) would be necessary to test our non-inferiority hypothesis. An interim analysis was scheduled to be performed when $1 / 5$ of the recruitment had been achieved, in order to assess colon cleanliness and safety. Finally, the following tests were used for the final analysis : the Mac Nemar test, the chi-square test and the Student's t-test on paired data. A $p$ value $<0.05$ was deemed to be statistically significant.

\section{RESULTS}

\section{Patients}

The flow distribution of the 545 patients enrolled in the trial is shown in Fig. 1. The demographic characteristics of the intention-to-diagnose cohort are shown in Table 2.

\section{Propulsion of the capsule and colon cleanliness}

Interim analysis of colon cleanliness was performed after enrolment of the first 105 patients ${ }^{7}$. Although there were no safety concerns, the proportion of patients with good or excellent preparation was only $55 \%$. Thus, the protocol was amended and the recommendation ${ }^{3}$ concerning the use of a completely clear liquid diet the day before CCE was adopted. Despite this change in the preparation, there was no improvement in the quality of preparation (data not shown) and results concerning cleanliness were pooled in the final analysis. As indicated by Fig. 2, colon cleanliness was considered to be excellent or good in $52 \%$ of patients at CCE and in $83 \%$ of cases at colonoscopy. In most patients (91\%), the capsule was excreted within 10 hours of ingestion.

\section{Prevalence and accuracy of detection of polyps}

Table 3 shows the per-patient prevalence of polyps and CRC detected by colonoscopy and the diagnostic performance of CCE. Overall, colonoscopy detected more patients with polyps than did CCE. Hence, 311 (57\%) patients had polyps of any size detected by colonoscopy compared with 249 seen at CCE $(46 \% ; p<0.0001)$. Regarding polyps $\geq 6 \mathrm{~mm}$ and $\geq 10 \mathrm{~mm}$, 
R1 manuscript Sacher-Huvelin et al

the corresponding figures were $112(21 \%)$ versus $94(17 \%)(p=0.097)$ and $43(8 \%)$ versus $29(5 \%)(p=0.03)$, respectively.

Five patients with CRC were detected by colonoscopy compared with only three detected by CCE. The two missed cancers were located in the sigmoid colon and rectum, and both were relatively large tumours (35 $\mathrm{mm}$ and $15 \mathrm{~mm}$, respectively). Re-reading of the videos of these two cancer cases failed to detect any abnormality that could have been missed by previous readers. The quality of preparation was good in one case and fair in the other case.

For the 545 patients, the CCE accuracy of detection of polyps $\geq 6 \mathrm{~mm}$ or CRC was $39 \%(95 \% \mathrm{Cl} 30-48)$ for sensitivity, $88 \%(95 \% \mathrm{Cl} 85-91)$ for specificity, $47 \%$ (95\% Cl 37-57) for the positive predictive value (PPV) and $85 \%(95 \% \mathrm{Cl} 82-88)$ for the negative predictive value (NPV). The non-inferiority between CCE and colonoscopy for the detection of polyps $\geq$ $6 \mathrm{~mm}$ was not acceptable for sensitivity (absolute difference $-51 \%(95 \% \mathrm{Cl}-58 ;-43)$ nor for NPV (absolute difference $-13 \%(95 \% \mathrm{Cl}-16 ;-10)$.

For 118 patients, the results of CCE and colonoscopy were discordant concerning the primary criterion of judgment. All of the CCE videos of these discordant cases were reviewed by the expert panel. This reinterpretation of the capsule videos improved the diagnostic yield of CCE, with sensitivity increasing to $57 \%$ (95\% Cl $48-66)$, specificity to $95 \%$ (95\% Cl 93-97), PPV to $73 \%(95 \% \mathrm{Cl} 63-82)$ and NPV to $90 \%(95 \% \mathrm{Cl} 87-92)$.

With respect to advanced adenomas (i.e. adenomas $\geq 10 \mathrm{~mm}$ and/or with a villous contingent and/or high grade dysplasia), the sensitivity of CCE was better, at $72 \%$, and an NPV of $94 \%$.

Overall, the results were almost the same in the screening and surveillance cohorts (data not shown) and in the intention-to-diagnose and per-protocol cohorts (data not shown).

\section{Effect of cleanliness on the accuracy of CCE}

As shown in Fig. 3, CCE accuracy was better in the group of patients with good or excellent cleanliness compared with those with poor or fair preparation. In the well-prepared patients, 
R1 manuscript Sacher-Huvelin et al

the NPV increased to $88 \%(95 \% \mathrm{Cl} 83-92)$ for polyps $\geq 6 \mathrm{~mm}$ and $98 \%(95 \% \mathrm{Cl} 96-99)$ for polyps $\geq 10 \mathrm{~mm}$, but sensitivity remained low (53\% [95\% Cl 39-67]) for polyps $\geq 6 \mathrm{~mm}$ ).

\section{Effect of modifying the gold standard on the accuracy of CCE and colonoscopy}

The consideration of false positives of the CCE procedure as true positives, if confirmed by the expert panel (or, in four cases, by a second colonoscopy), minimised the differences in accuracy between CCE and colonoscopy for the diagnosis of polyps $\geq 6 \mathrm{~mm}$. Indeed, the sensitivity and specificity of CCE increased to 51\% (95\% Cl 42-59) and 94\% (95\% Cl 91-96), respectively, compared with $83 \%(95 \% \mathrm{Cl} 76-89)$ and $100 \%$ for colonoscopy. Similarly, PPV and NPV were $72 \%(95 \% \mathrm{Cl} 63-81)$ and $85 \%$ (95\% Cl 82-89), respectively, for CCE versus $100 \%$ and $95 \%$ (95\% Cl 93-97) for colonoscopy. Thus, even in the best-case scenario, CCE was unable to satisfy the conditions of non-inferiority, as compared with colonoscopy.

\section{Safety and tolerability}

Nineteen adverse events were reported. Most of these were of mild or moderate severity (Table 4). Only three severe adverse events occurred, which were either potentially related to bowel preparation. No severe adverse event was related to the capsule itself.

The comparison of VAS scores showed a slight (probably not clinically relevant) statistical difference in favour of CCE compared with colonoscopy $(8.74 \pm 1.56$ versus $8.25 \pm$ $2.00 ; p<0.0001)$

\section{DISCUSSION}

This study, the largest trial of CCE reported to date, confirms the feasibility, safety and tolerability of this method for the screening and surveillance of patients at average or increased risk of CRC. Despite an excellent NPV, the sensitivity of CCE was lower than in previous studies conducted in patients with already-known, or suspected, disease. Therefore, the hypothesis of non-inferiority of CCE compared with colonoscopy is ruled out by the present data. 
R1 manuscript Sacher-Huvelin et al

One strength of this study was the enrolment of a representative population of patients referred for screening or surveillance. The demographic characteristics of our cohort are indeed those expected in this context ${ }^{8-11}$, although we enrolled fewer average-risk than increased-risk subjects. The proportion of polyps detected was slightly higher than initially expected, which may, ultimately, have resulted in a minor underestimation of the NPV of CCE. However, the issue concerning the results of this study is not NPV, but rather sensitivity. There are several reasons that may have contributed to a lower sensitivity of CCE as compared with previous trials. The poor quality of bowel preparation in nearly half of the subjects is a plausible explanation, because colon cleanliness directly influences the diagnostic performance of CCE, as shown by Van Gossum et $\mathrm{al}^{3}$ and confirmed by the present study. However, our findings are in agreement with those recently reported (in an abstract form) by Spada et $\mathrm{al}^{12}$; indeed, in their series of 92 patients, only $43.5 \%$ of them had an adequate (good or excellent) bowel preparation. Accordingly the sensitivity of CCE in this study was somewhat lower $(56 \%)$ that in previous series ${ }^{1-4}$. In our study, the type of population enrolled (asymptomatic subjects) could be one of the factors that negatively influenced colon cleanliness. This does, however, reflect real-life conditions, where patients are prepared out of the clinic. In contrast, colonoscopy was performed on the second day in the clinic and in more stringent conditions; it is, therefore, not surprising that the preparation was considered good or excellent at colonoscopy in $83 \%$ of the cases. Moreover, the flushing of residual amounts of faeces may occur during colonoscopy (but not during CCE), which may further improve the quality of exploration by colonoscopy. In the group of patients with excellent or good colon cleanliness the sensitivity of CCE, although improved, remains clearly insufficient. In this respect it is important to underline that, in the first published metaanalysis ${ }^{13}$ of CCE trials, only data (including our preliminary results) referring to the best level of bowel preparation were included. The last meta-analysis published by Spada et $a{ }^{14}$ found a sensitivity of $68 \%$ for significant findings (polyps $\geq 6 \mathrm{~mm}$ and/or $\geq 3$ polyps). In fact, after excluding one study for heterogeneity, the sensitivity falls to $62 \%$. 
R1 manuscript Sacher-Huvelin et al

To the best of our knowledge there has been no validation study of the scale used for CCE colonic preparation assessment. We used the same scale as in previous CCE studies ${ }^{1-}$ 4, 12. We cannot completely exclude that, apart from true differences in the quality of preparation between centres, some part of the variability could be related to inter-observer variations in the assessment method employed. This may also contribute to an explanation of the wide variability in colonic preparation quality scores reported in the meta-analysis ${ }^{14}$, as the proportion of patients who were well prepared ranged from $27 \%$ up to $89 \%$.

Another reason for the lower performance of CCE in our study might be insufficient experience of the endoscopists in reading the CCE videos. This hypothesis is partly supported by the fact that the diagnostic yield improved upon re-reading of the videos of discordant cases by an expert panel, but again it did not reach the performance characteristics required for a screening or a surveillance procedure. However, we did not detect, in the context of this trial, any evidence of a learning curve effect. Indeed, no difference was observed in terms of diagnostic performance when we compared the group of 70 patients initially enrolled with the group of patients recruited later (data not shown). In addition, there was no difference between the low-volume recruitment centres and the largest ones. The differences between centres were actually more directly related to the overall quality of colonic preparation achieved in different hospital settings.

Finally, even after changing the gold standard definition to test the best possible scenario, the difference between CCE and colonoscopy remained outside the maximal interval accepted for the non-inferiority hypothesis. Hence, our negative conclusion concerning CCE sensitivity would seem to be robust and was unchanged by the several post-hoc analyses performed in selected subgroups. Similarly, the results were not better in the per-protocol cohort or in the average-risk compared with increased-risk patients.

The main criterion of judgement adopted in this trial (i.e. the proportion of patients with polyps of at least $6 \mathrm{~mm}$ or $\mathrm{CCR}$ ) is the same as in other studies. It is justified by the fact that the risk of cancer is very low (but not zero) below this size threshold. As with other imaging technologies, such as CT-scanning (virtual colonoscopy), CCE does not allow the 
R1 manuscript Sacher-Huvelin et al

removal of polyps and, thus, it has been proposed that small, diminutive polyps do not need to be removed, due to the very low risk of malignancy ${ }^{10,15,16}$. In contrast, the detection and removal of advanced adenomas is of crucial importance. In this context, it is important to stress the excellent NPV and the better sensitivity of CCE, reaching $72 \%$ for the whole cohort (and $78 \%$ in the well-prepared patients). CCE might, at least, be an option when colonoscopy is contra-indicated or incomplete for technical reasons and further trials are in progress to test this potential "second-line" indication of CCE.

All diagnostic parameters were calculated on a per-patient analysis. Therefore it is not surprising to see that sensitivity is better for small than large polyps. Indeed, the number of small polyps was higher than that of large polyps (for example, 177 out of 857 polyps had a diameter of at least $6 \mathrm{~mm}$ compared to 54 for those of at least $10 \mathrm{~mm}$ ). Therefore, the likelihood of detecting a polyp in a patient is greater for small polyps, because their mean number per patient is higher (0.32) than for large polyps $(0.10)$.

One limitation inherent to all current capsule endoscopy technologies is the difficulty of assessing polyp size accurately. Although we applied the same principles as in former studies, it must be recognised that the method used in all CCE studies provides an imperfect estimate, which clearly may have affected the validity of our primary criteria of judgement. The second generation of capsule endoscopes will, hopefully, integrate a better system with respect to the measurement of polyp size. Our study was not designed to assess inter/intraobserver variability but within the panel of experts who reviewed the discordant cases the inter-observer agreement was $71 \%$ (data not shown)

Finally, it must be acknowledged that we used a first generation of colon capsule. Very-recently, a new device has been developed, which presents several technical improvements, including a larger field-of-view, a better sampling rate and, of greater importance, a grid for more objective measurement of polyp size. A recent trial of this new device $^{17}$ conducted in a population with various colonic pathologies, reported higher sensitivity than in our study but, again, the population was not representative of a screening population, as in our trial. 
R1 manuscript Sacher-Huvelin et al

In summary, in this trial, which involved the largest population enrolled for colon capsule evaluation to date, and which was conducted in average- and increased-risk, asymptomatic patients, we did not establish the non-inferiority of CCE as compared with colonoscopy. Further studies should pay particular attention to colonic preparation in conditions compatible with real life. Quality control of video reading is probably required after an initial training period. Improving the technology of the device is, on its own, probably insufficient to fulfil the requirements of a test which is useful for screening and surveillance in patients at risk of CRC. 
R1 manuscript Sacher-Huvelin et al

\section{References}

1. Eliakim R, Fireman Z, Gralnek IM, et al. Evaluation of the PillCam colon capsule in the detection of colonic pathology: results of the first multicenter, prospective, comparative study. Endoscopy 2006;38:963-70.

2. Schoofs N, Devière J, Van Gossum A. PillCam colon capsule endoscopy compared with colonoscopy for colorectal tumor diagnosis: a prospective pilot study. Endoscopy 2006;38:971-7.

3. Van Gossum A, Munoz-Navas M, Fernandez-Urien I, et al. Capsule endoscopy versus colonoscopy for the detection of polyps and cancer. $\mathrm{N}$ Engl $\mathrm{J}$ Med 2009;361:264-70.

4. Gay G, Delvaux M, Frederic M, et al. Could the colonic capsule PillCam colon be clinically useful for selecting patients who deserve a complete colonoscopy?: Results of clinical comparison with colonoscopy in the perspective of colorectal cancer screening. Am J Gastroenterol 2010;105:1076-86.

5. Galmiche JP, Coron E, Sacher-Huvelin S. Recent developments in capsule endoscopy. Gut 2008;57:695-703.

6. Bossuyt PM, Reitsma JB, Bruns DE, et al. The STARD statement for reporting studies of diagnostic accuracy: explanation and elaboration. Ann Intern Med 2003;138:1-12.

7. Sacher-Huvelin S, Le Rhun M, Sébille V, et al. Wireless Capsule Colonoscopy Compared to Conventional Colonoscopy in Patients At Moderate or Increased Risk for Colorectal Cancer. Interim Analysis of a Prospective Multicenter Study [abstract]. Gastroenterology 2009;69 (suppl 1):A53.

8. Le Rhun M, Coron E, Parlier D, et al. High resolution with chromoscopy versus standard colonoscopy for the detection of colonic neoplasia: a randomized study. Clin Gastroenterol Hepatol 2006;4: 349-54.

9. Johnson CD, Chen $\mathrm{MH}$, Toledano $\mathrm{AY}$, et al. Accuracy of CT colonography for detection of large adenomas and cancers. N Engl J Med 2008;359:1207-17.

10. Pickhardt PJ, Choi JR, Hwang I, et al. Computed tomographic virtual colonoscopy to screen for colorectal neoplasia in asymptomatic adults. N Engl J Med 2003;349: 2191-200.

11. Harewood GC, Lieberman DA. Colonoscopy practice patterns since introduction of medicare coverage for average-risk screening. Clin Gastroenterol Hepatol 2004;2:727.

12. Spada C, Hassan C, Riccioni ME, et al. Pillcam colon capsule endoscopy for colon exploration: a single centre Italian experience [abstract]. Gastrointest Endosc 2010;71:AB203.

13. Rokkas T, Papaxoinis $K$, Triantafyllou $K$, et al. Meta-analysis evaluating the accuracy of colon capsule endoscopy in detecting colon polyps. Gastrointest Endosc 2010;71:792-8.

14. Spada C, Hassan C, Marmo R et al. Meta-analysis shows colon capsule endoscopy is effective in detecting colorectal polyps. Clin Gastroenterol Hepatol 2010;8:516-522.

15. Bond JH. Clinical relevance of the small colorectal polyp. Endoscopy 2001;33:454-7. 
R1 manuscript Sacher-Huvelin et al

16. Külling $D$, Christ $A D$, Karaaslan $N$, et al. Is histological investigation of polyps always necessary? Endoscopy 2001;33:428-32.

17. Eliakim R, Yassin K, Niv Y, et al. Prospective multicenter performance evaluation of the second-generation colon capsule compared with colonoscopy. Endoscopy 2009;41:1026- 
R1 manuscript Sacher-Huvelin et al

Table 1: Study protocol: colonic preparation and drug administered (prokinetic and boosters)

Day -3 to -2

Low residue diet

Idem

Day -1

Low residue diet

Liquid diet

18:00 - 21:00

3 litres Colopeg®

Idem

19

20

Day +1

$6: 00-7: 00$

1 litre Colopeg $\AA$

8:00 - 9:00

20 mg Motilium® \& PillCam

Day 0

$12: 00$

Booster I (45 ml NaP)*

Idem

15:30

Booster II (30 ml NaP) **

18:00

10 mg Bisacodyl suppository**

18:30

Low-fibre snack

After 10:00

1 litre Colopeg $\AA$

Traditional colonoscopy

Idem

* Pending verification that PillCam left stomach with RAPID real-time viewer

** If PillCam was not expelled from anus 
R1 manuscript Sacher-Huvelin et al

Table 2: Demographic characteristics of the intention-to-diagnose cohort

\section{Average risk $^{\star} \quad$ Increased risk ${ }^{\star} \quad$ Total}
$N=163$
$N=376$
$N=545^{\star}$

$\begin{array}{llll}\text { Age (years; mean range) } & 60(27-79) & 60(25-86) & 60(25-86) \\ \text { Gender F/M } & 76 / 87 & 162 / 214 & 306 / 239\end{array}$

Family history $\mathrm{N}(\%)$

$\begin{array}{llll}\text { Polyps } & 0 & 63(12) & 63(12) \\ \text { CRC } & 0 & 184(34) & 184(34)\end{array}$

Personal history N (\%)

$\begin{array}{llll}\text { Polyps } & 0 & 213(39) & 213(39) \\ \text { CRC } & 0 & 18(3) & 18(3)\end{array}$

*6 missing data items concerning the criterion of inclusion: average/increased risk Age and gender were not statistically different between groups 
R1 manuscript Sacher-Huvelin et al

Table 3: The prevalence of lesions detected by colonoscopy in the 545 patients in the accuracy analysis and the sensitivity, specificity, positive predictive value and negative predictive value of CCE for the detection of these lesions.

\section{Colonoscopy}

Prevalence Sensitivity

$\mathrm{N}$ of patients (\%)

\section{Colon Capsule Endoscopy}

\begin{tabular}{|c|c|c|}
\hline Specificity & $\begin{array}{l}\text { Positive } \\
\text { Predictive } \\
\text { Value }\end{array}$ & $\begin{array}{c}\text { Negative } \\
\text { Predictive } \\
\text { Value }\end{array}$ \\
\hline
\end{tabular}

$\%(95 \% \mathrm{Cl})$

Polyp

$\begin{array}{lccccc}\text { Any size } & 311(57.1) & 58(53-64) & 71(65-77) & 73(67-78) & 56(50-62) \\ \geq 6 \mathrm{~mm} & 112(20.6) & 39(30-48) & 88(85-91) & 47(37-57) & 85(82-88) \\ \geq 10 \mathrm{~mm} & 43(7.9) & 35(21-49) & 97(96-99) & 52(34-70) & 95(93-97)\end{array}$

Adenoma

Any size

$192(35.2)$

$61(54-68)$

$63(58-68)$

$47(41-53)$

$75(70-80)$

$\geq 6 \mathrm{~mm}$

$80(14.7)$

$44(33-55)$

87 (84-90)

$37(27-47)$

$90(87-93)$

$\geq 10 \mathrm{~mm}$

$36(6.6)$

$39(23-55)$

97 (96-99)

$48(30-66)$

$96(94-97)$

Advanced adenoma*
Any size
54 (9.9)
$72(60-84)$
57 (53-62)
$16(11-20)$
$94(92-97)$
$\geq 6 \mathrm{~mm}$
45 (8.3)
49 (34-63)
$86(83-89)$
$23(15-32)$
95 (93-97)
$\geq 10 \mathrm{~mm}$
$36(6.6)$
$39(23-55)$
97 (96-99)
$48(30-66)$
$96(94-97)$
Colorectal Cancer**
$5(0.9)$
$60(17-100)$
$100(99-100)$
$60(17-100)$
$100(99-100)$

* Advanced adenoma was defined as an adenoma $10 \mathrm{~mm}$ or larger or an adenoma with villous features or high grade dysplasia.

${ }^{* *}$ All colorectal cancers were larger than $10 \mathrm{~mm}$ and localised, one in the caecum, one in the rectum and three in the sigmoid colon. 
2

\begin{tabular}{|l|l|l|l|l|}
\hline \multicolumn{1}{|c|}{ Adverse event } & \multicolumn{1}{c|}{ Number of } & \multicolumn{1}{c|}{ Severity } & Relation & Evolution \\
& \multicolumn{1}{|c|}{ patients } & & & \\
\hline Haemorrhoid proctitis & 1 & Moderate & Probable & Resolved \\
\hline Vomiting & 7 & Mild & Probable & Resolved \\
\hline Hypokalaemia & 1 & Mild & Probable & Resolved \\
\hline Cervical pain & 1 & Mild & Probable & Resolved \\
\hline Dizzyness & 1 & Moderate & Probable & Resolved \\
\hline $\begin{array}{l}\text { Bleeding after } \\
\text { mucosectomy }\end{array}$ & 1 & Severe & Probable & Resolved \\
\hline Fever & 2 & & & \\
\hline Headache & 1 & Mild & None & Resolved \\
\hline Abdominal pain & 1 & Mild & None & Resolved \\
\hline Bronchospasm & 1 & Mild & Probable & Resolved \\
\hline Colonic perforation & 1 & Mild & Probable & Resolved \\
\hline Cardiac failure & 1 & Severe & Probable & Resolved \\
\hline
\end{tabular}

Table 4: Adverse events

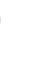

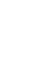

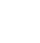
. 1

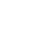

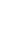

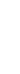

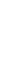
(n)

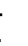

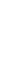

R1 manuscript Sacher-Huvelin et al 
R1 manuscript Sacher-Huvelin et al

\section{Figure Legends}

Figure 1: Flow of patients. Intention-to-diagnose and per-protocol cohorts.

Figure 2: Proportion of patients (\%) with excellent or good colonic preparation at colon capsule endoscopy and colonoscopy.

Figure 3: Capsule accuracy of capsule endoscopy in patients with good or excellent cleanliness. 
R1 manuscript Sacher-Huvelin et al

\section{Acknowledgments}

\section{The authors thank the following people for their contribution in this study:}

The expert panel for the re-reading of CCE:

Bernard Filoche, Gérard Gay, Vincent Maunoury, Sylvie Sacher-Huvelin

The investigators, listed from highest to lowest number of patients enrolled in the study:

Jean Paul Galmiche, Marc Le Rhun, Emmanuel Coron, Mathurin Flamant, Marianne Gaudric, Stanislas Chaussade, Romain Coriat, Robert Benamouzig, Bakhtiar Bejou, JeanChristophe Saurin, Thierry Ponchon, Jérôme Dumortier, Marie George Lapalus, Jeanne Boitard, Clément Subtil, Patrice Couzigou, Elise Chanteloup, Eric Terreborne, Michel Delvaux, Muriel Frédéric, Philippe Ducrotté, Stéphane Lecleire,Christophe Cellier, Joel Edery, Camille Savale, Dimitri Coumaros, Dimitri Tzilves, Denis Heresbach, Pierre Nicolas d'Halluin, Denis Sautereau, Anne Lesidaner, Franck Cholet, Thierry Barrioz.

The following people participated in the coordination of the study:

Stéphanie Bardot, Kafia Belhocine, Kevin Galery, Eliane Hivernaud, Anne Omnes, Véronique Sébille, Fabienne Vavasseur 
R1 manuscript Sacher-Huvelin et al

\section{Financial support and Statement of interest}

Author's declaration of personal interest

Robert Benamouzig is a board membership of Given Imaging.

Jean Paul Galmiche is a consultant of Given Imaging.

\section{Declaration of funding interest}

This study was funded by a national grant from the French Ministry of Health and sponsored by the Délégation à la Recherche Clinique (DRC) of the university hospital of Nantes.

The study benefited from some limited logistic support from Given Imaging, including the use of an already-available eCRF and a discount price for capsules. The design of the trial and the monitoring and analysis of data were, however, conducted independently by the sponsor (DRC) and the authors. 
R1 manuscript Sacher-Huvelin et al

\section{STARD checklist for reporting of studies of diagnostic accuracy}

(version January 2003)

\begin{tabular}{|c|c|c|c|}
\hline Section and Topic & $\begin{array}{c}\text { Item } \\
\#\end{array}$ & & On page \# \\
\hline $\begin{array}{l}\text { TITLE/ABSTRACT/ } \\
\text { KEYWORDS }\end{array}$ & 1 & $\begin{array}{l}\text { Identify the article as a study of diagnostic accuracy (recommend MeSH } \\
\text { heading 'sensitivity and specificity'). }\end{array}$ & 2 \\
\hline INTRODUCTION & 2 & $\begin{array}{l}\text { State the research questions or study aims, such as estimating diagnostic } \\
\text { accuracy or comparing accuracy between tests or across participant } \\
\text { groups. }\end{array}$ & 3 \\
\hline \multicolumn{4}{|c|}{ Pe } \\
\hline \multirow[t]{4}{*}{ Participants } & 3 & $\begin{array}{l}\text { The study population: The inclusion and exclusion criteria, setting and } \\
\text { locations where data were collected. }\end{array}$ & 4 \\
\hline & 4 & $\begin{array}{l}\text { Participant recruitment: Was recruitment based on presenting symptoms, } \\
\text { results from previous tests, or the fact that the participants had received } \\
\text { the index tests or the reference standard? }\end{array}$ & 4 \\
\hline & 5 & $\begin{array}{l}\text { Participant sampling: Was the study population a consecutive series of } \\
\text { participants defined by the selection criteria in item } 3 \text { and } 4 \text { ? If not, } \\
\text { specify how participants were further selected. }\end{array}$ & 4 \\
\hline & 6 & $\begin{array}{l}\text { Data collection: Was data collection planned before the index test and } \\
\text { reference standard were performed (prospective study) or after } \\
\text { (retrospective study)? }\end{array}$ & 4 \\
\hline \multirow[t]{5}{*}{ Test methods } & 7 & The reference standard and its rationale. & 4 \\
\hline & 8 & $\begin{array}{l}\text { Technical specifications of material and methods involved including how } \\
\text { and when measurements were taken, and/or cite references for index } \\
\text { tests and reference standard. }\end{array}$ & 5 \\
\hline & 9 & $\begin{array}{l}\text { Definition of and rationale for the units, cut-offs and/or categories of the } \\
\text { results of the index tests and the reference standard. }\end{array}$ & 3 \\
\hline & 10 & $\begin{array}{l}\text { The number, training and expertise of the persons executing and reading } \\
\text { the index tests and the reference standard. }\end{array}$ & 5 \\
\hline & 11 & $\begin{array}{l}\text { Whether or not the readers of the index tests and reference standard } \\
\text { were blind (masked) to the results of the other test and describe any } \\
\text { other clinical information available to the readers. }\end{array}$ & 5 \\
\hline \multirow[t]{2}{*}{ Statistical methods } & 12 & $\begin{array}{l}\text { Methods for calculating or comparing measures of diagnostic accuracy, } \\
\text { and the statistical methods used to quantify uncertainty (e.g. } 95 \% \\
\text { confidence intervals). }\end{array}$ & 6 \\
\hline & 13 & Methods for calculating test reproducibility, if done. & NA \\
\hline \multicolumn{4}{|l|}{ RESULTS } \\
\hline \multirow[t]{3}{*}{ Participants } & 14 & $\begin{array}{l}\text { When study was performed, including beginning and end dates of } \\
\text { recruitment. }\end{array}$ & 4 \\
\hline & 15 & $\begin{array}{l}\text { Clinical and demographic characteristics of the study population (at least } \\
\text { information on age, gender, spectrum of presenting symptoms). }\end{array}$ & $\begin{array}{c}7 \text { and } \\
\text { table } 2\end{array}$ \\
\hline & 16 & $\begin{array}{l}\text { The number of participants satisfying the criteria for inclusion who did or } \\
\text { did not undergo the index tests and/or the reference standard; describe } \\
\text { why participants failed to undergo either test (a flow diagram is strongly } \\
\text { recommended). }\end{array}$ & $\begin{array}{l}7 \text { and } \\
\text { figure } 1\end{array}$ \\
\hline \multirow[t]{4}{*}{ Test results } & 17 & $\begin{array}{l}\text { Time-interval between the index tests and the reference standard, and } \\
\text { any treatment administered in between. }\end{array}$ & Table 1 \\
\hline & 18 & $\begin{array}{l}\text { Distribution of severity of disease (define criteria) in those with the target } \\
\text { condition; other diagnoses in participants without the target condition. }\end{array}$ & $\begin{array}{l}7 \text { and } \\
\text { table } 2\end{array}$ \\
\hline & 19 & $\begin{array}{l}\text { A cross tabulation of the results of the index tests (including } \\
\text { indeterminate and missing results) by the results of the reference } \\
\text { standard; for continuous results, the distribution of the test results by the } \\
\text { results of the reference standard. }\end{array}$ & Table 3 \\
\hline & 20 & $\begin{array}{l}\text { Any adverse events from performing the index tests or the reference } \\
\text { standard. }\end{array}$ & $\begin{array}{l}9 \text { and } \\
\text { Table } 4\end{array}$ \\
\hline
\end{tabular}


R1 manuscript Sacher-Huvelin et al

\begin{tabular}{|l|c|l|c|}
\hline Estimates & 21 & $\begin{array}{l}\text { Estimates of diagnostic accuracy and measures of statistical uncertainty } \\
\text { (e.g. 95\% confidence intervals). }\end{array}$ & $\begin{array}{c}7,8,9 \\
\text { and table } \\
3\end{array}$ \\
\hline & 22 & $\begin{array}{l}\text { How indeterminate results, missing data and outliers of the index tests } \\
\text { were handled. }\end{array}$ & $\begin{array}{c}7 \text { and } \\
\text { figure } 1\end{array}$ \\
\hline & 23 & $\begin{array}{l}\text { Estimates of variability of diagnostic accuracy between subgroups of } \\
\text { participants, readers or centers, if done. }\end{array}$ & $\begin{array}{c}7,9 \\
\text { table } 3 \\
\text { and } \\
\text { figures } 2 \\
\text { and 3 }\end{array}$ \\
\hline & 24 & Estimates of test reproducibility, if done. & NA \\
\hline DISCUSSION & 25 & Discuss the clinical applicability of the study findings. & $9,10,11$ \\
\hline
\end{tabular}


Figure 1: Flow of patients. Intention-to-diagnose and per-protocol cohorts. $85 \times 51 \mathrm{~mm}(400 \times 400 \mathrm{DPI})$ 


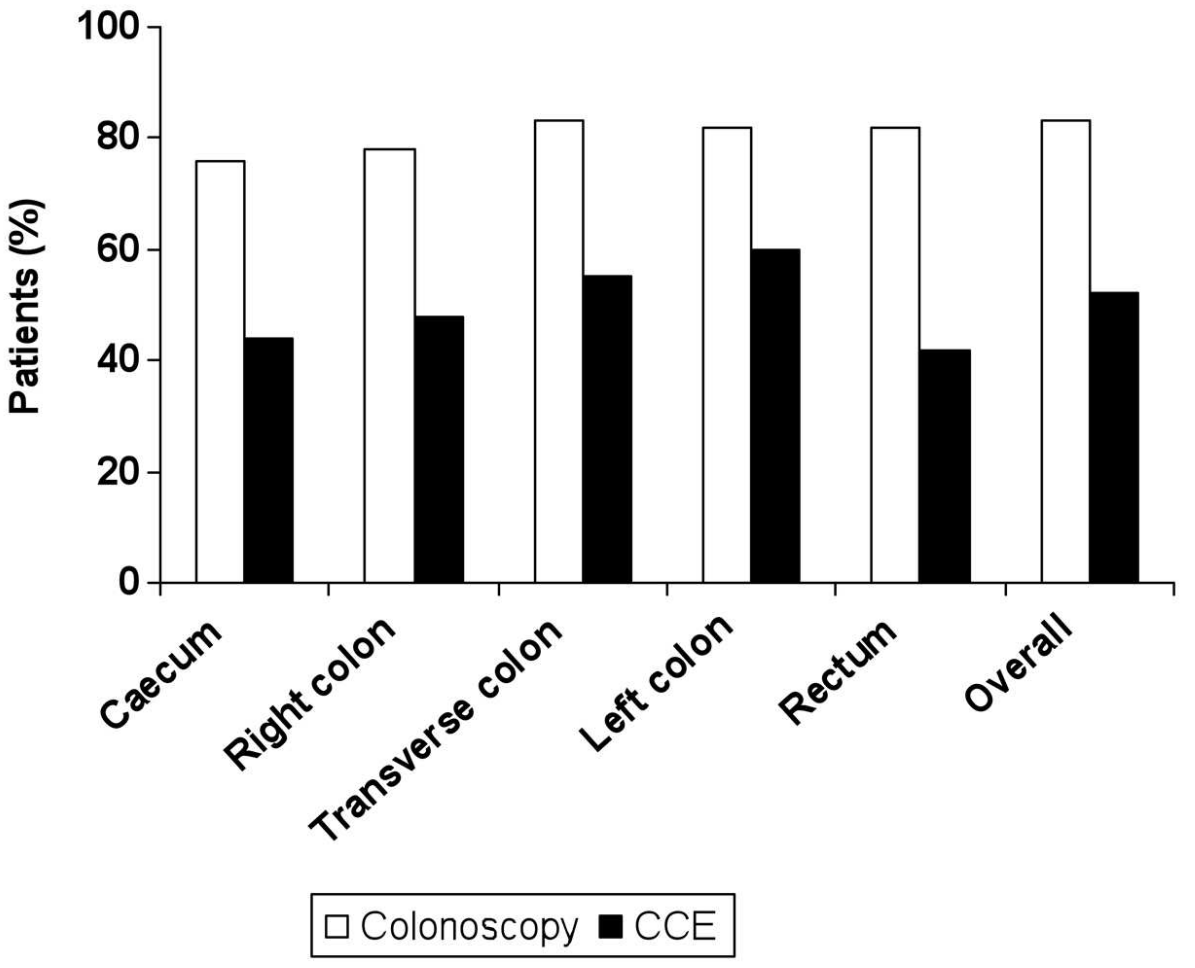

Figure 2: Proportion of patients (\%) with excellent or good colonic preparation at colon capsule endoscopy and colonoscopy. $85 \times 68 \mathrm{~mm}(400 \times 400 \mathrm{DPI})$ 


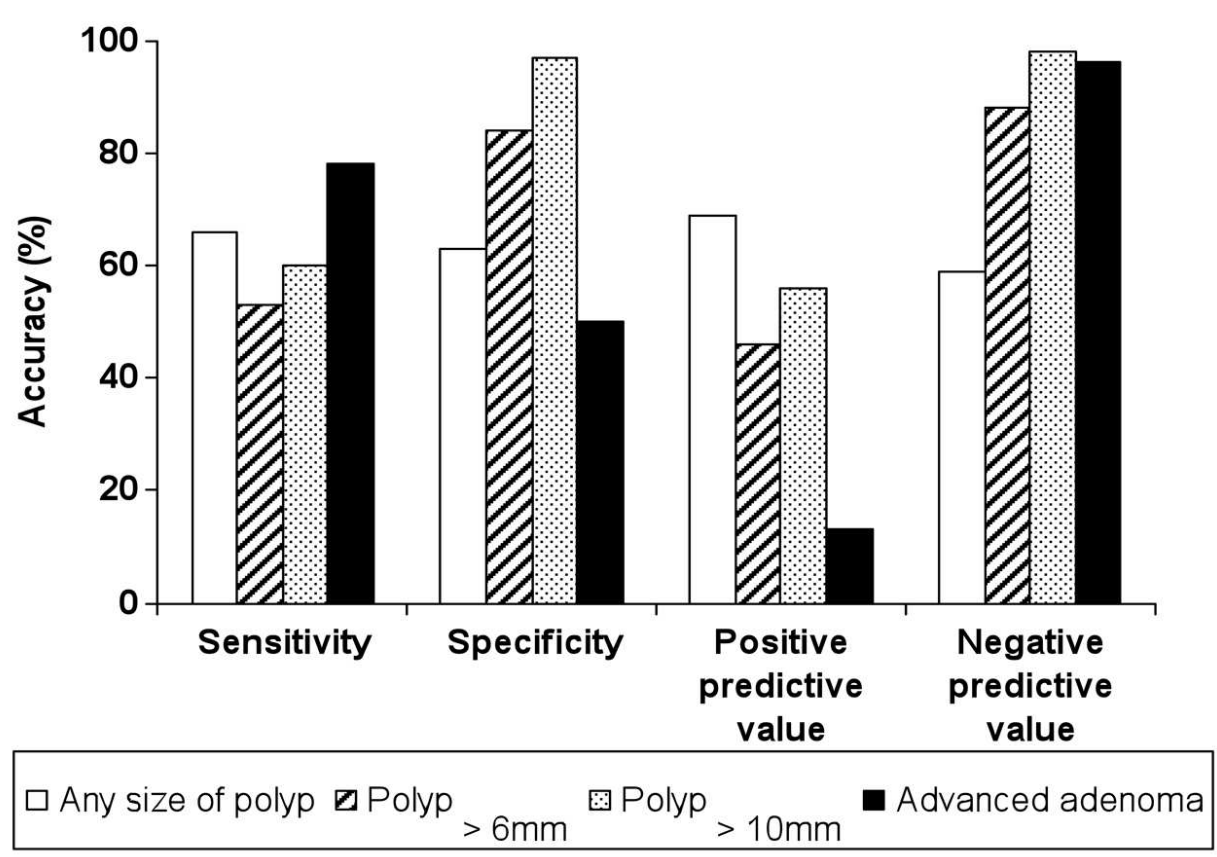

Figure 3: Capsule accuracy of capsule endoscopy in patients with good or excellent cleanliness. $85 \times 64 \mathrm{~mm}(400 \times 400 \mathrm{DPI})$ 